\title{
Status Dystonicus: A Rare Manifestation of Cerebral Palsy
}

\author{
Venika Tyagi $^{1} \cdot$ Anika Agrawal $^{1}$ (D) $\cdot$ Devendra Mishra $^{1} \cdot$ Monica Juneja $^{1}$
}

Received: 21 November 2019 / Accepted: 21 January 2020 / Published online: 8 February 2020

(C) Dr. K C Chaudhuri Foundation 2020

To the Editor: Status dystonicus (SD), also known as dystonic storm or dystonic crisis, is a rare life-threatening movement disorder emergency [1] characterized by severe, generalized and continuous hyperkinesias. The course and outcome of SD is highly variable, but early recognition facilitates aggressive intervention, which could potentially prevent progression and favor a better outcome [1].

We herein describe the clinical presentation and management of an episode of SD in a 1.5-y-old patient with dyskinetic cerebral palsy. The child was born through nonconsanguineous marriage with no significant birth history, however requiring exchange transfusion on day 5 of life. The mother noticed looseness of all four limbs at 3 mo of age and sporadic abnormal movements with developmental delay at 9 mo of age for which the child was started on antiepileptics and physiotherapy. The child presented to our hospital with relentless dystonic spasms, severe opisthotonus with retrocollis, excessive drooling and irritability for 1 day accompanied by an upper respiratory tract infection. The investigations revealed metabolic derangements including deranged kidney function tests, elevated creatine kinase and metabolic acidosis. A possibility of grade 4 SD was kept and the child was started on pacitane, clonazepam and oral clonidine. In view of poor control, syndopa, midazolam infusion and tetrabenzine were added sequentially. Midazolam infusion was tapered and stopped once dystonias improved. However, her sensorium continued to be depressed which showed a marked improvement on stopping tetrabenzine. The child was discharged on pacitane and clonazepam.

In the longest series published on SD, majority of patients $(37.8 \%)$ were affected by secondary dystonia with cerebral

Anika Agrawal

dranikaagrawal@gmail.com

1 Department of Pediatrics, Maulana Azad Medical College, New Delhi, India palsy being the most common cause [2]. There are no established guidelines or standardized therapeutic approaches for the treatment of SD [1]. Pharmacological intervention has been established as the first-line strategy in majority of the episodes (tetrabenazine and benzhexol being most effective) followed by a stepwise approach: sedation (benzodiazepines and propofol followed by barbiturate anesthesia), neurosurgery, and rarely muscle paralysis or intrathecal baclofen (ITB) [3-5]. Trial with syndopa should always be given in children with dystonia of unknown etiology due to the clinical variability of the dopa-responsive dystonias [1].

\section{Compliance with Ethical Standards}

Conflict of Interest None.

\section{References}

1. Allen NM, Lin JP, Lynch T, King MD. Status dystonicus: a practice guide. Dev Med Child Neurol. 2014;56:105-12.

2. Fasano A, Ricciardi L, Bentivoglio AR, et al. Status dystonicus: predictors of outcome and progression patterns of underlying disease. Mov Disord. 2012;27:783-8.

3. Ruiz-Lopez M, Fasano A. Rethinking status dystonicus. Mov Disord. 2017;32:1667-76.

4. Teive HA, Munhoz RP, Souza MM, et al. Status dystonicus: study of five cases. Arq Neuropsiquiatr. 2005;63:26-9.

5. Iodice A, Pisani F. Status dystonicus: management and prevention in children at high risk. Acta Biomed. 2019;90:207-12.

Publisher's Note Springer Nature remains neutral with regard to jurisdictional claims in published maps and institutional affiliations. 